\title{
A HISTÓRIA DA PRAÇA JOÃO ALVES E SUA CONTRIBUIÇÃO NA PAISAGEM DA CIDADE
}

\author{
THE HISTORY OF JOÃO ALVES SQUARE AND ITS CONTRIBUTION FOR THE CITY'S \\ LANDSCAPE
}

\section{MACIEL, Marieta Cardoso}

Engenheira arquiteta, urbanista e paisagista, e professora doutora do Departamento de Projetos da Escola de Arquitetura/UFMG.

E-mail: marietamaciel@hotmail.com

\section{RESUMO}

A arquitetura da paisagem se insere na tarefa integrada de uso, preservação, recuperação e reinvenção dos cenários urbanos a partir da história de uma cidade e de seus potenciais ambientais. Então pode-se construir lugares, preservar outro e assim recuperar as tradições locais. Com isso a cidade vive não só sua origem, mas também seu futuro. A paisagística deve atuar de acordo com as mudanças sociais, modificando os cenários urbanos sem alterar as suas raízes, as riquezas naturais e culturais que já existem. Praças públicas são alguns desses espaços. As características ambientais do lugar é que direcionam o desenho, o caráter e o tipo de intervenção paisagística. Os usuários e os órgãos gestores da cidade são essenciais para o projeto, sua execução, gestão e conseqüentemente na permanência da sua vida contemporânea. Um projeto de praça pública tem como objetivo o encontro da coletividade, a organização e a construção da paisagem do lugar. É o que esse trabalho vai apresentar, exemplificando os conceitos da paisagística através do projeto da praça João Alves, no bairro de Venda Nova, em Belo Horizonte - executado em 2001 - e que criou uma nova história para aquele bairro, suas pessoas e para a cidade. De um espaço subutilizado, de modo privado e indevido como depósito de ferro-velho, ponto ilegal de carroceiros (que por estar entre duas grandes artérias viárias poderia integrar dois bairros adjacentes) foi transformado num lugar adequado para o recreio e o encontro coletivo. Assim, cumpriu sua função urbana de polarização, e passou a ser utilizado por grande número de pessoas como uma praça de fato. O novo cenário paisagístico mudou a história do lugar que um dia foi um depósito de lixo. Entretanto tudo não passou de uma breve história. A gestão regional desconsiderou a dinâmica urbana da praça que foi liberada à fruição pública. Atualmente a praça está sendo destruída e sua paisagem reinventada pela população.

Palavras-chave: História, contemporâneo, praça, paisagem, gestão.

\begin{abstract}
Landscape architecture is placed inside the integrated task of use, preservation, retrieval and reinvention of urban landscapes. All this based upon a city's background and its environmental potentials. So, it is possible to build something, to preserve something else and to recover local traditions. The city then lives not only its past but its future. The landscaping must act according to social changes, modifying urban landscapes without changing its roots, natural and cultural resources that already exists. Public squares are some of those spaces. The place's environmental characteristics direct the drawing, character and type of landscape intervention. Users and city management departments are essential to the project, its execution and management. A public square project intends to promote the meeting of collectivity, organization and construction of the place's landscape. That's what this work is going to present, showing the project of Joano Alves Square (Venda Nova, Northern area of Belo Horizonte, built in 2001) as an example of applied landscape concepts. This plan created a new scene for that area, its people and to the city. From an underused space, privately and improperly used as a junk deposit, illegal spot of carroceiros (it's in between two arterial roads and could connect two adjacent blocks), it was transformed into a proper place for entertainment and collective gathering. Therefore, the place met its urban goal of polarization and started being used as a proper square
\end{abstract}


by a number of users. The new landscape changed the place's history of being a junk deposit. However, it was all but a short tale. The local management desconsidered the square urban dynamics. Today, it's being destroyed and its landscape reinvented by the population.

\section{Key words: History, contemporary, square, landscape, management.}

\section{1 - Introdução}

As praças e parques públicos são parte do espaço urbano construído e, portanto, arquitetura. $\bigcirc$ desenho das cidades, sejam planejadas pelo urbanismo ou pela sua espontânea expansão físico territorial, gera uma primeira configuração tanto das praças quanto dos parques. A arquitetura da paisagem ${ }^{1}$ é que se incumbe dos desenhos internos.

A ocorrência de grandes ocupações humanas e a grave e constante degradação do meio biofísico, paralelamente à expansão das ciências ambientais, impõem novas condutas à arquitetura.

A consciência ecológica e a coletiva têm se desenvolvido tornando esses espaços valorizados. Atualmente, os órgãos públicos se preocupam com essas questões, uma vez que exista a tendência da superpopulação em detrimento da racionalização da ocupação físico-territorial.

No caso de Belo Horizonte (BH), ações de controle ambiental têm sido tomadas pelos órgãos competentes, procurando compatibilizar o adensamento populacional com os espaços públicos disponíveis e trazer a melhoria da qualidade de vida. A construção de praças e parques públicos de $\mathrm{BH}$ faz parte dessas ações que têm como meta o aproveitamento racional dos recursos ambientais existentes, proporcionando o desenvolvimento sustentável do ambiente urbano.

As praças ${ }^{2}$ e os parques públicos abrigam os movimentos e as paradas de coisas e pessoas. Têm como finalidade a sustentação física e social dessas atividades. São lugares onde todos podem passar, neles permanecer, encontrar, contemplar e que trazem a sensação do bem estar individual e coletivo podendo com isso até transformar a cidade.

As praças de $\mathrm{BH}$ são muitas, mas, espalhadas de forma não planejada pela cidade não são suficientes para atender o uso público, seja pela quantidade e qualidade o que provoca tensões nas questões da qualidade do seu meio ambiente.

Como as demais metrópoles, BH se reconstrói. São edifícios que desaparecem cedendo lugar a outros e a outras paisagens. Dentro desse processo de mutação e de reocupação dos espaços urbanos, as praças podem ser redesenhadas, quando necessário, pela arquitetura paisagística. A sua função urbana, entretanto, é constante, ou seja, espaços que contam a história do lugar, atraentes, acessíveis e com ambientes internos que proporcionam sua fruição popular.

$\mathrm{O}$ ambiente $^{3}$ de $\mathrm{BH}$ se compõe dessas paisagens que estão relacionadas com a abrangência perceptiva do homem. As praças e os parques são espaços livres de edificações que em conjunto com os edificados constituem os cenários urbanos que a arquitetura paisagística se incumbe de estruturar.

Os projetos em arquitetura paisagística ou ambientais urbanos são designações de tipos de projetos pertencentes à arquitetura. Os de praças e parques públicos de $\mathrm{BH}$ considerados os seus valores sociais e ecológicos são indutores das cenas urbanas. A praça João Alves é aqui relatada e descrita com o objetivo de demonstrar o procedimento do seu projeto, execução e a necessidade de políticas de gestão. Consiste na elaboração do projeto, dos seus caminhos e na relação direta dos desenhos com a construção, fator decisivo para que exista a arquitetura. Todos os passos metodológicos são dissecados, investigando-se e compreendendo-se os seus caminhos, apoiados em resultados precedentes e na análise dos procedimentos adotados.

Tais dados, sejam teóricos ou práticos, constituem respostas gráficas possíveis na resolução de um problema espacial. $\bigcirc$ profissional em arquitetura paisagística encontra, na dinâmica de $\mathrm{BH}$, 
razão suficiente para a elaboração de projetos de praças e parques que ofereçam ao público alvo propostas desenhadas que induzam à criação de novas paisagens e novos espaços para a fruição do lazer público. Dessa forma, os Espaços Livres de Uso Público ${ }^{4}$ destinados ao recreio de $\mathrm{BH}$ poderão exercer a sua função urbana e a melhoria ambiental na cidade.

Belo Horizonte tem 330,90 km², e cerca de $80 \%$ constituem espaços urbanizados formados por espaços edificados e livres, públicos e privados. Restam poucos espaços livres, públicos e privados, que constituem, além das praças e parques, as vias de circulação e elementos naturais que ainda resistem, como montanhas, córregos, matas e lagoas.

Devido à rápida e descontínua ocupação territorial foram detectados alguns problemas relacionados com as praças de $\mathrm{BH}$, tais como:

- Escassez de novos loteamentos que são uns dos geradores das praças;

- demanda pública atual de praças inversamente proporcional à oferta;

- praças cujos projetos arquitetônicos paisagísticos não foram executados têm suas áreas invadidas ou usadas inadequadamente;

- existência de grande número de praças públicas que não têm o projeto arquitetônico paisagístico que é o fator indutor da sua construção e uso público;

- escassez de recursos e desarticulação dos procedimentos e normas municipais tanto para a elaboração dos projetos de praças e parques públicos em $\mathrm{BH}$, como para sua execução e principalmente a sua manutenção.

Os espaços edificados se ampliam, se expandem e reduzem os espaços livres, públicos e privados. A qualidade de vida, o meio ambiente urbano e as paisagens se alteram constantemente. A dinâmica ocorrida no meio ambiente belo-horizontino, nos 109 anos de sua existência, impõe a adoção de novos enfoques na manutenção e conservação de praças e parques, objetivando sua efetiva função urbana e garantindo a preservação, recuperação e/ou a reinvenção da paisagem urbana.

\section{2 - Valor urbano das praças}

Belo Horizonte do século XIX representava, através do seu desenho regular e geométrico, a racionalidade do planejamento urbano pós-revolução industrial. Conseqüentemente os espaços livres e públicos da cidade assumiram configurações geométricas. As praças são parte deles.

Atualmente, nas cidades contemporâneas, os espaços amenizadores da vida urbana são as praças, os jardins e os parques, que contem praças e jardins, todos espaços livres públicos de uso coletivo. As praças públicas são espaços raros e escassos hoje em dia e valorizados pelos benefícios físicos e sociais trazidos à população. Nelas, o recreio, o lazer a sociabilidade, contrapõem-se ao trabalho, ao tempo escasso e às atividades repetitivas.

As praças públicas são também marcos físicos, lugares referenciais da micro e macropaisagem, seja pelo valor biofísico, seja pelo valor cultural, pois contam a história, a vida e a personalidade da cidade. As praças mudam suas características funcionais e formais quando a cidade muda e porque os cidadãos também mudaram. É a dinâmica urbana contada pelas praças e seus espaços livres e públicos. Daí, a sua importância na história da cidade e das suas paisagens. Os espaços edificados e os livres, públicos e privados configuram a cidade. As praças estão inseridas neste contexto. É o paisagismo que trata dos estudos das praças e seu valor na cons186 trução da paisagem urbana.

As praças públicas atendem diretamente à população vizinha e indiretamente à região. Elas têm dimensões físicas menores que as dos parques e raramente têm vegetação e fauna significativa. Não deve existir rigidez nos critérios pois podem variar pelas condições biofísicas e sociais da 
cada local. Os ambientes podem ser isolados dos ruídos, do tráfego; ora sombreados, ora ensolarados, e a intensidade de uso público deve ser compatível com a sua capacidade biofísica e espacial. São início ou fim das vias públicas adjacentes, são espaços de paradas nas circulações urbanas e lugar da cultura.

As condicionantes biofísicas e sócio econômica lugar onde se localizam, transmitem o tipo ou o caráter às praças públicas: quando em zonas comerciais e industriais adquirem características referentes à pureza e à saúde, sendo um fator terapêutico para o local. Amenizam a polvição visual, sonora e de partículas e contrastam com os espaços edificados. Quando em zonas residenciais oferecem ambiências recreativas, educacionais e culturais como se fossem extensões das casas.

As praças, qualquer que seja o tipo, são elementos identificadores da cidade, estão sempre ligadas à sua história e cultura.

\section{3 - Praças de Belo Horizonte}

Belo Horizonte foi concebida a partir de um projeto urbanístico de Aarão Reis que previa praças e jardins, um amplo parque e um jardim zoológico. Foi inaugurada em 1897 dentro dos modelos urbanísticos da época.

O desenho da nova capital surpreendia pelo contraste com a cidade de Ouro Preto, antiga capital, com traçados sinuosos que acompanhava o lugar montanhoso. As ruas curvas contrapunham-se às largas e retas avenidas de $\mathrm{BH}$ que ainda proporcionam grandes visadas panorâmicas.

O traçado é regular, em tabuleiro de xadrez, com grandes avenidas que se interceptam ortogonalmente, sendo que as principais praças da cidade localizam-se nessas interseções. Conseqüentemente elas têm sempre configurações geométricas, tais como: quadradas, retangulares, circulares e triangulares.

$\mathrm{Na}$ cidade de $\mathrm{BH}$, foram previstas as zonas verdes, os cinturões verdes, as praças, os parques, a arborização das ruas e avenidas. O lugar do Parque Municipal foi escolhido por Aarão Reis para o lazer público. Foi lá que Aarão Reis sonhou a cidade e o tornou ponto referencial do seu desenho. $O$ parque e as praças compreendidas na zona urbana nasceram com o desenho da cidade planejada. $O$ projeto previa ainda espaços para o Jardim Zoológico, o Hipódromo e a arborização da cidade.

Entretanto, tais espaços ou não chegaram a ser implementados ou foram sendo gradativamente ocupados por outros tipos de uso no decorrer do processo de urbanização.

O processo de ocupação do espaço planejado foi lento, enquanto as zonas suburbanas e sítios eram parcelados a revelia.

Somente em 1940 através do Decreto n. 84, de 24 de dezembro, o Código de Obras, o processo de uso e ocupação do solo em BH obedecia a uma organização.

Muitos loteamentos clandestinos ocorreram nessa época, ocasionando descontinuidade e inadequação com o sistema viário do espaço planejado além da grande ocupação de espaços edificados na superfície física territorial do município e redução dos espaços livres de uso público.

Mesmo nos parcelamentos devidamente aprovados pela $\mathrm{PMBH}$, os espaços livres de uso público eram inaproveitáveis para o fim proposto. Localizados em regiões acidentadas como grotas, talvegues, fundo de vales ou cristas de morro, inviabilizava a sua transformação em praças e propiciou a invasão e ocupação por parte de uma população mais carente.

Em 1979 foi aprovada a Lei Federal n. 6.766/79 que regulamenta e direciona o Parcelamento do Solo Urbano. Legislação importantíssima para o equilíbrio quantitativo e qualitativo entre 


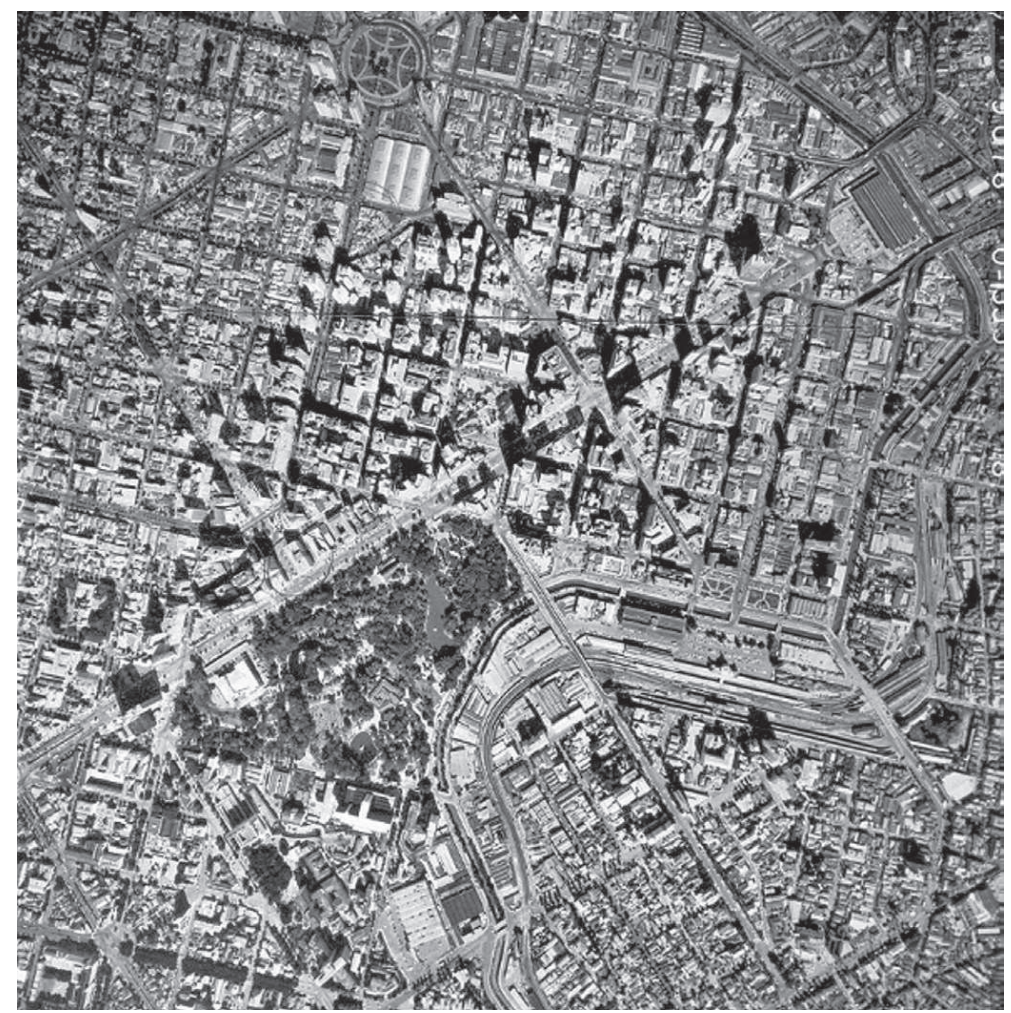

Figura 1: Vista aérea: centro de BH

Fonte: MACIEL, 1999

os espaços edificados e os espaços livres nas cidades brasileiras. Infelizmente a maioria das nossas cidades, independente do seu porte, desconhece ou não atende aos preceitos legais nela estabelecidos.

Belo Horizonte se antecipou nestas questões e talvez por isso ainda exista uma certa harmonia entre os elementos naturais e artificiais na sua paisagem.

As praças ainda são geradas pelos parcelamentos do solo. São poucas, mas cada vez mais importantes na morfologia da cidade e na sua qualidade de vida.

As praças têm valor ecológico, social, educacional, recreativo e paisagístico. É nas praças e nos parques públicos que se desenvolve o lúdico, a arte, os deslocamentos, o encontro, a liberdade. Intervalos entre as atividades quotidianas e o sentimento do "não fazer", da diversão, do descanso são necessários. É nas praças e parques públicos que a cultura, o lúdico, o encontro podem ser concretizados, proporcionando a revitalização emocional, física e ética do homem nas cidades.

Através de investigações foi constatada (MACIEL, 1999) a necessidade de projetos arquitetônicos paisagísticos para as praças de BH. Diante de dados obtidos em 1998 das 477 praças legalmente disponíveis na cidade, 268 praças não têm projetos arquitetônicos paisagísticos o que equivale a $56 \%$ de praças que não cumprem a sua função urbana. Apenas a Regional Centro Sul tem suas praças implantadas quase na sua totalidade, mas outro problema aparece como a adequação da intensidade do uso público com a gestão do espaço e a manutenção periódica necessárias ao desenvolvimento das suas funções urbanas.

Torna-se importante ressaltar que a melhoria da qualidade de vida em Belo Horizonte é tarefa árdua e continuará a ser enfrentada por todas as futuras administrações, dependendo principalmente da gestão ambiental a ser desenvolvida por elas. Para isso, os órgãos públicos, as empresas privadas e a população em geral precisam ter a consciência dessa realidade, da importância desses espaços na cidade para a otimização da qualidade de vida de todos que nela vivem. Muitas praças e parques não implantados devem ter projetos arquitetônico-paisagísticos definidos para que, a partir deles, se obtenham a expansão do seu valor social, cultural e paisagístico. 


\section{4 - Praça João Alves}

Venda Nova é uma das nove administrações regionais de Belo Horizonte, situada no vetor norte da cidade distinguindo-se por sua autonomia comercial, serviços e institucional. A ocupação planejada só ocorreu a partir da década de setenta o que gerou uma carência de espaços livres de uso público implantados e disponibilizados à fruição dos cidadãos.

Conforme a Lei Ambiental Municipal n. 4.253/85 a construção da Estação de Venda Nova faz parte do Plano Municipal de Transporte Coletivo elaborado pela Companhia de Transporte de Belo Horizonte (BHTRANS) em 2000. O empreendimento foi analisado, aprovado e obtida a Licença de Implantação (LI) no Conselho Municipal de Meio Ambiente (COMAM). A praça João Alves foi uma das medidas compensatórias estabelecidas pelo Conselho para amenizar o impacto negativo do empreendimento na região e por ser uma demanda já identificada no Orçamento Participativo (OP) elaborado pela comunidade envolvida.

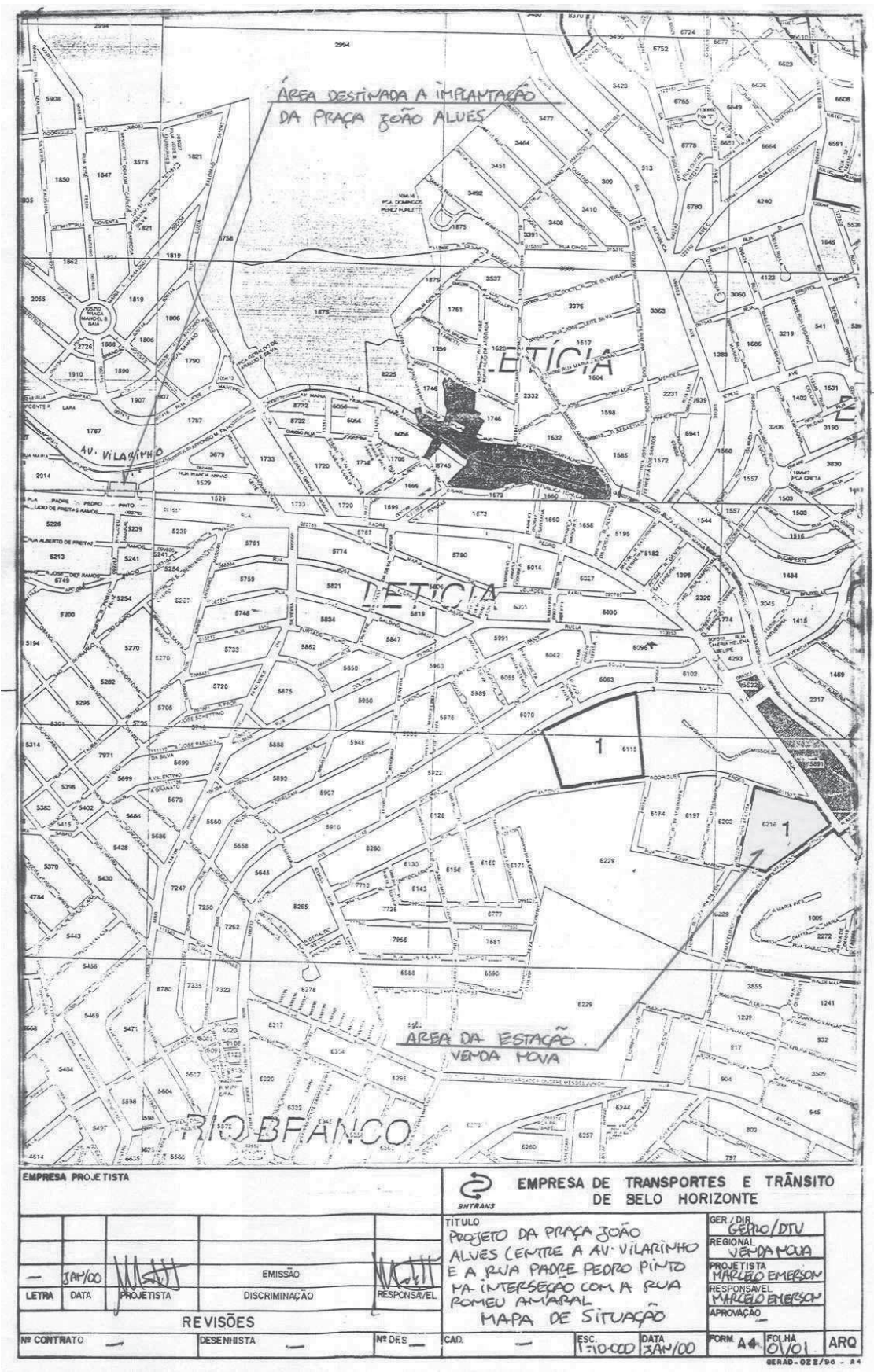

Figura 2: Mapa de situação Fonte: WAGNER et al., 2000 
Descreveremos a seguir alguns pontos relevantes caracterizadores das condições ambientais existentes em Venda Nova e necessárias à contextualização e elaboração da proposta Arquitetônica e Paisagística da praça.Os dados foram extraídos dos Estudos de Impacto Ambiental (EIA), do Relatório de Impacto Ambiental (RIMA) apresentados quando de sua aprovação no COMAM e trabalho da disciplina paisagismo da pós-graduação da EAUFMG-2000 (WAGNER et al. 2000).

Em 1984, o Distrito de Venda Nova passou a se chamar Administração Regional de Venda Nova, uma das nove administrações regionais do Município de Belo Horizonte. Conta com 44 bairros e 13 vilas e população estimada em 350.000 habitantes.

Está localizada a noroeste de $\mathrm{BH}$ e tem como limites os municípios de Ribeirão das Neves, Vespasiano, Pedro Leopoldo e Santa Luzia. Ocupa uma extensão físico territorial aproximada de $86 \mathrm{~km}^{2}$.

O centro multifuncional da regional está localizado ao longo da rua Padre Pedro Pinto que em conjunto com a avenida Vilarinho são as principais vias articuladoras da região com o centro metropolitano.

Os espaços livres, públicos e coletivos para uso recreativo, especificamente as praças, são raros na região. Existem muitos espaços livres, mas de propriedade privada.

Aos domingos a população utiliza a avenida Vilarinho como lugar de encontro e atividades coletivas como feiras, esportes e eventos culturais. As demais atividades são desenvolvidas em espaços particulares. Na regional se localiza o parque Alexander Brandt que apesar dos raros equipamentos atenua a carência do recreio público. Também é utilizado esporadicamente o Parque Lagoa do Nado que não pertence a regional, mas é próximo.

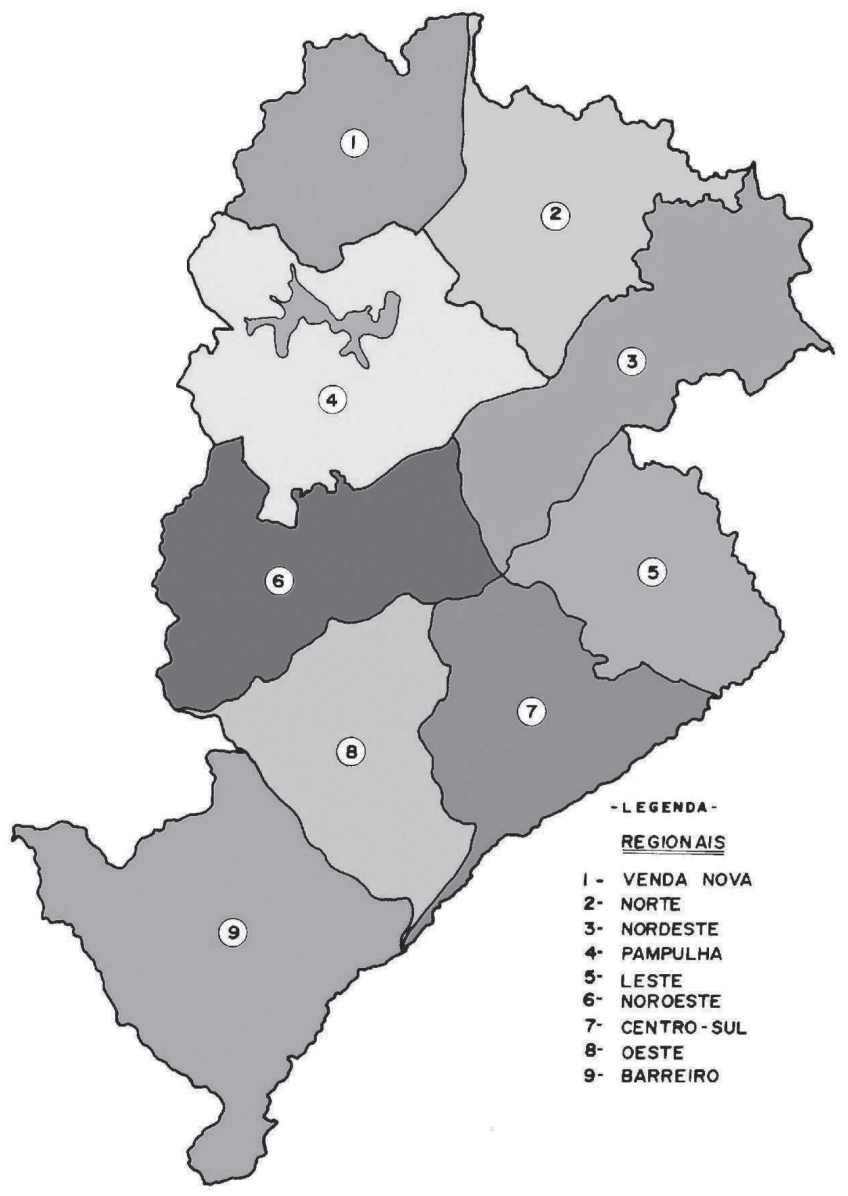

Figura 3: Regional Norte Fonte: MACIEL, 1999 
A avenida Padre Pedro Pinto é estrutural na morfologia da regional, é o eixo de convergência das principais vias de acesso e ponto tradicional de Venda Nova. A avenida Maria Vieira Barbosa, vulgo Vilarinho, construída no talvegue do córrego vem alterando a configuração do lugar e a sua história: São canais de circulação que integram os bairros da porção norte da regional e tem como finalidade a articulação do sistema viário existente, envolvendo veículos e pedestres, com o restante do município.

Quanto às características biofísicas, a regional recebe os ventos dominantes vindos da direção leste e que contribuem para uma temperatura média anual de $22^{\circ} \mathrm{C}$. Predominam no relevo as colinas de topo plano com encostas convexas e altitudes entre 800 e $900 \mathrm{~m}$, entrecortadas por vales amplos de fundo chato, na maioria colmados por sedimentos argilosos. A região está localizada na depressão periférica de Belo Horizonte, limitada pelo macroestrutura do Supergrupo Minas e da bacia sedimentar Bambuí. O tipo de solo é residual. Em áreas acidentadas apresenta-se arenoso e suscetível a erosões.

As condições hidrológicas da região são decorrentes da bacia hidrográfica do córrego Vilarinho e do Isidoro, pertencente a do Onça e a do rio das Velhas e a do rio São Francisco. Ocorrem inundações freqüentes pela velocidade da canalização do córrego do Vilarinho que recebe uma vazão acelerada pela constante urbanização.

A fauna e flora local foi intensamente alterada pela ocupação antrópica descaracterizando a cobertura vegetacional e consequentemente o habitat natural.

A praça João Alves foi desenhada, pelo loteamento de 1987, de traçado geométrico regular, um retângulo com dimensões de 55 por $45 \mathrm{~m}$ e superfície total de $2.475 \mathrm{~m}^{2}$. Está localizada entre as avenidas Padre Pedro Pinto e Vilarinho, e duas ruas locais sem nome.

A ocupação do loteamento e seu entorno acontecia gradativamente com os usos residenciais unifamiliar e misto localizados de um lado das avenidas Padre Pedro Pinto e Vilarinho, e os usos comerciais e serviços, nos quarteirões entre as duas vias coletoras. Nota-se a desintegração física e funcional entre os três segmentos e dificuldades de acessos tanto de pedestres como de veículos pois as duas vias são paralelas e não existe pontos de conexões.

A praça João Alves assume, então, pela sua localização um papel estratégico na circulação local de veículos e de pedestres. A configuração da praça também se alterou. Incorporou as ruas locais e foi acrescentada uma rua central, que serve de drenagem na região devido ao pequeno desnível entre as duas avenidas.

Como a maioria das praças em $\mathrm{BH}$ não existia o projeto de paisagismo o que dificultou a utilização pública seja como um rotor, passagens, paradas, lazer ou ornamento.

Para a elaboração do estudo preliminar da praça foram analisadas as condicionantes ambientais, entrevistas com a vizinhança e associações comunitárias, imagens fotográficas e principalmente a identificação dos elementos naturais do lugar e os elementos artificiais (espaços edificados e espaços livres), ou seja, a estrutura compositiva da paisagem.

O procedimento de elaboração do projeto de paisagismo seguiu os trâmites legais e profissionais em que o estudo preliminar foi apresentado, analisado, avaliado e aprovado pelas associações de moradores do local e do entorno. Em seguida foi elaborado o projeto executivo, a licitação e execução das obras. $O$ desenho representa o conceito, o caráter e a cultura daquele lugar. A nova paisagem teve como objetivo a substituição da qualidade ambiental da paisagem anterior seja pela intensidade do uso público como pela sua expressão plástica.

A extensão superficial e o relevo do terreno são alguns definidores do desenho interno das praças. É o plano de base, o elemento arquitetônico suporte das atividades públicas previstas conforme condicionantes ambientais, é o elemento que predomina visualmente na composição 

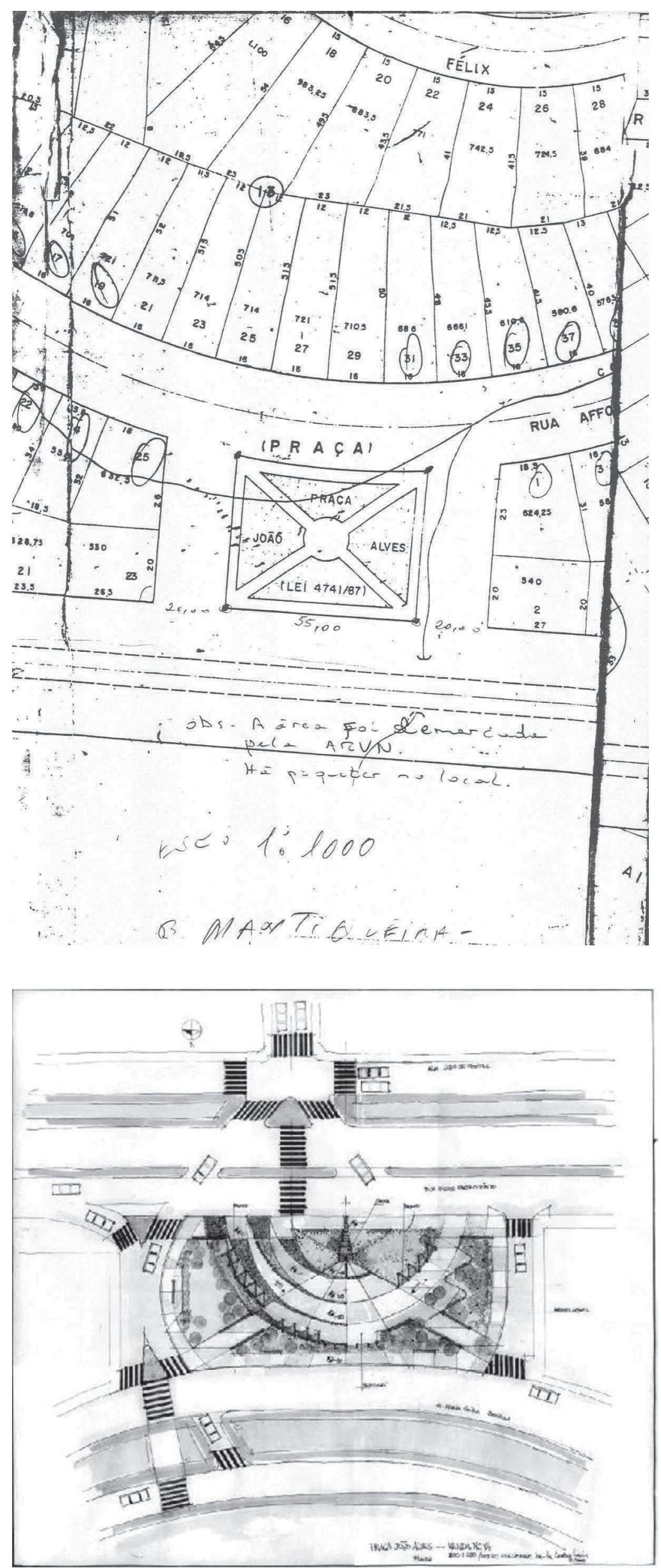

Figura 4: Loteamento

Fonte: Marieta Maciel, 2001
Figura 5: Estudo preliminar

Fonte: Marieta Maciel, 2001 
arquitetônica paisagística e estrutura os demais elementos, artificiais (entre os quais os arquitetônicos) e naturais. São classificadas segundo a permeabilidade entre o espaço aéreo, o solo e o subsolo, ou seja, a percolação hídrica, aeróbica e térmica. São impermeáveis quando impedem a troca de energia entre a água, o ar, o calor e o frio e a terra. Os equipamentos necessários às atividades recreativas, à circulação, às paradas ou funções públicas pré-estabelecidas devem ser localizadas nestas áreas.

A praça João Alves como um todo é um ornamento para quem passa e fica, e recebe em seus ambientes equipamentos adequados às atividades recreativas, culturais, permanências e movimentos. Foi planejada para o público local, bastante diversificado pela faixa etária e interesses. As áreas impermeáveis receberam tratamento técnico-construtivo que caracterize formalmente a sua ambiência. $\bigcirc$ ambiente central é hierarquicamente o mais importante em termos de capacidade de uso e intimidade é propício também para concentrações maiores de público através de feiras, festas e eventos coletivos. O plano de base, nesse caso foi revestido com placas de concreto colorido inter-travado e semi-permeável que possibilitou o uso de cores e texturas. Equipamentos como pérgulas, bancos e brinquedos foram dispostos de forma a abrigar e induzir as atividades coletivas como também contribuir com a expressão plástica da praça.

As áreas permeáveis, do plano de base são aquelas onde ocorre a troca energética „, através da permeabilidade, entre o ar, a água, a terra e o calor/frio. São áreas adequadas para introdução ou permanência de espécies vegetais. A combinação da volumetria (porte, cor, e texturas) da vegetação confere a praça personalidade e naturalidade. $\mathrm{Em} \mathrm{BH}$ é recomendado que pelo menos um terço da área total da praça seja de áreas permeáveis. Estes dois tipos de superfícies, juntos, definem o desenho interno das praças. Na praça João Alves foram utilizadas vegetações arbórea, palmeiras, trepadeiras, arbustos, forrações e pisos vegetais que tem finalidade climáticas, ornamentais e funcionais.

Os planos de fechamento das praças são compostos pela volumetria dos espaços edificados e dos espaços livres, vias de circulação, arborização urbana, matas e outros elementos naturais existentes, que dá identificação da praça no lugar.

A cobertura é imaginária, virtual, mas existente, percebida pela sua ambiência, mas pode ser visível e concreta como a pérgula contínua que oferece mais uma opção de estar.

A acessibilidade da praça está diretamente ligada ao relevo do plano de base e das vias de circulação. Quanto mais contato a praça tiver para com o entorno, maior sua integração ao uso público, seja visual, física, psicológica ou imaginária.

Quando a praça se conecta com as vias públicas em toda a sua extensão, eles se integram e potencializam a intensidade do uso público. Se esse plano está mais alto ou rebaixado, existe uma descontinuidade no acesso e desintegração com as vias públicas, diminuindo assim a intensidade do uso público. No caso da praça João Alves, existe um desnível suave entre o lado adjacente a avenida Padre Pedro Pinto que é mais elevada que o lado da avenida Vilarinho, consequentemente as ruas laterais são inclinadas mas sem afetar a acessibilidade da praça.

Com relação à acessibilidade visual da praça com o contexto, quando o plano de base for mais elevado em relação às ruas, tem-se uma visão superior e destacada do entorno. Entretanto, quando o plano é rebaixado, existe a desintegração visual de dentro da praça, mas obtém-se um ambiente mais aconchegante e protegido, menos exposto.

Infelizmente, foi executada apenas a obra da praça. As ruas laterais, as travessias de pedestres e ilhas foram esquecidas o que ocasionou, sem dúvidas, a inacessibilidade de sua utilização pública. A paisagem local transformou-se com a praça, mas não cumpriu a sua função urbana. Ainda que tenha tido os percursos que interligam os seus ambientes, a praça não se ligou com o entorno tornando-se uma ilha. 


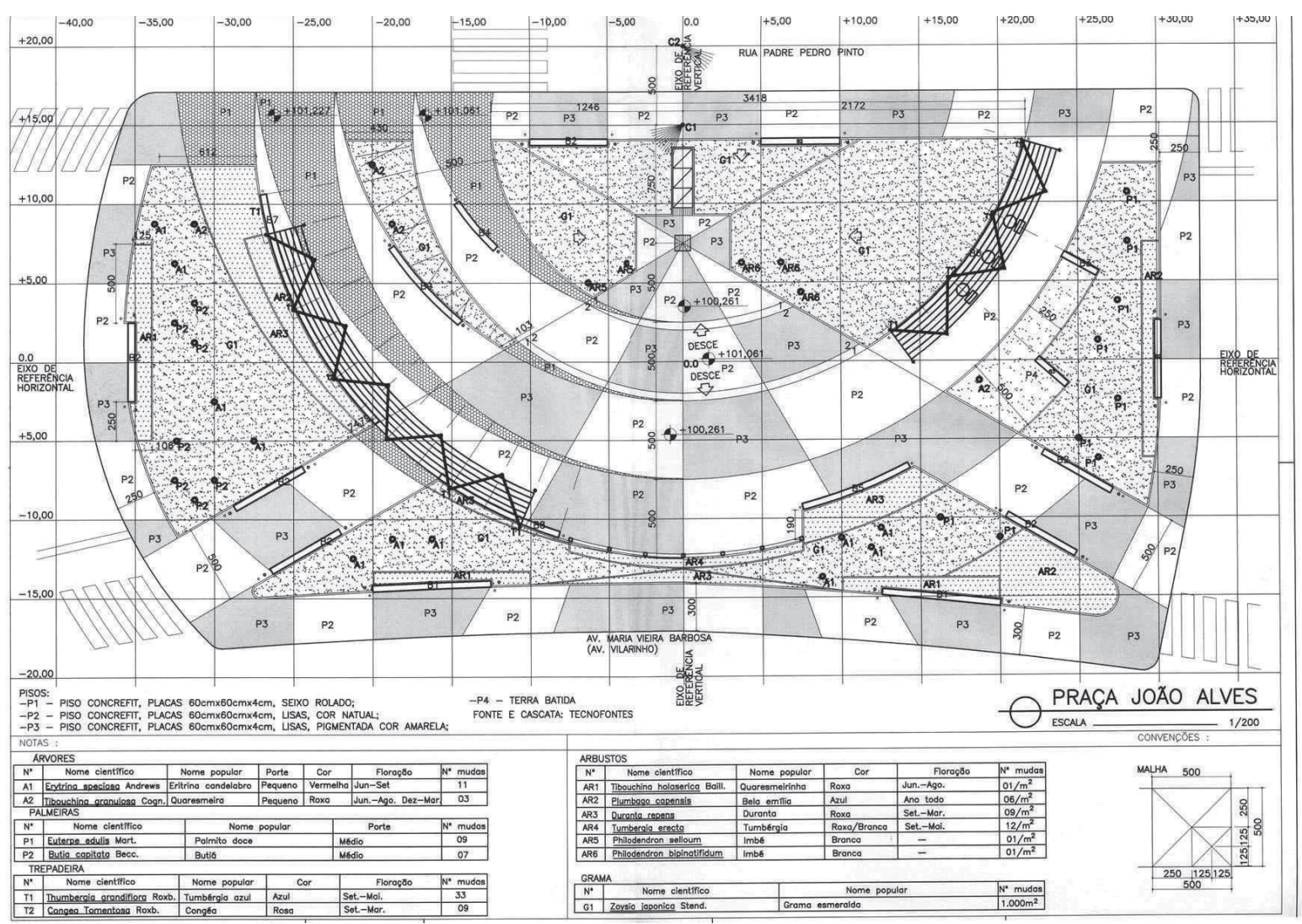

Figura 6: Projeto executivo

Fonte: Marieta Maciel, 2001
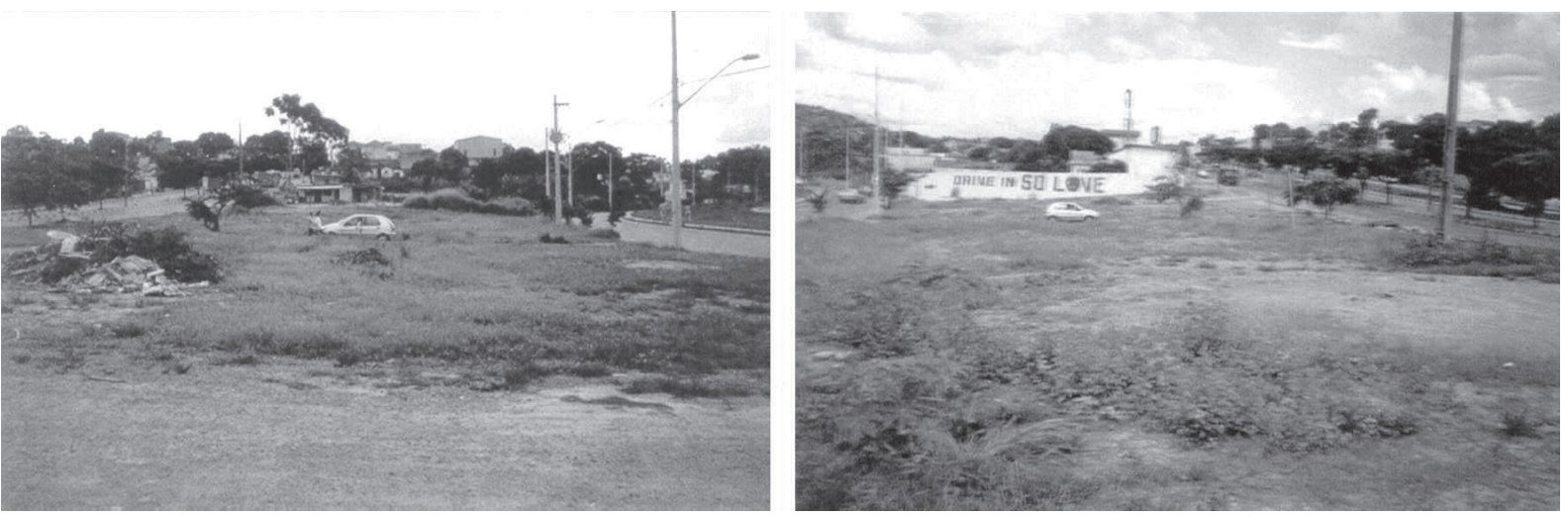

Figura 7: Paisagem original

Fonte: Acervo do autor

A expressão plástica da praça é revelada por toda a sua composição volumétrica, cromática e de texturas que dimensiona a intensidade e a atração dos impactos visuais. $\bigcirc$ desenho externo juntamente com o interno constituem sua aparência visual. As praças devem ser atraentes, agradáveis e confortáveis para o público em geral.

A vegetação é composta de espécies resistentes, de preferência nativas, ou adaptadas ao clima, de fácil aquisição, manutenção, durabilidade e reposição. É também o habitat da fauna que é o elemento vivo que deve estar presente nas praças. Representa o valor ecológico da praça.

A água é um embelezamento natural, podendo ser aproveitada artificialmente nas suas variações dinâmicas: lagos, cursos d'água, cascatas e repuxos. Sugere o descanso e cria microclimas específicos. Razão da cascata e do repuxo. 

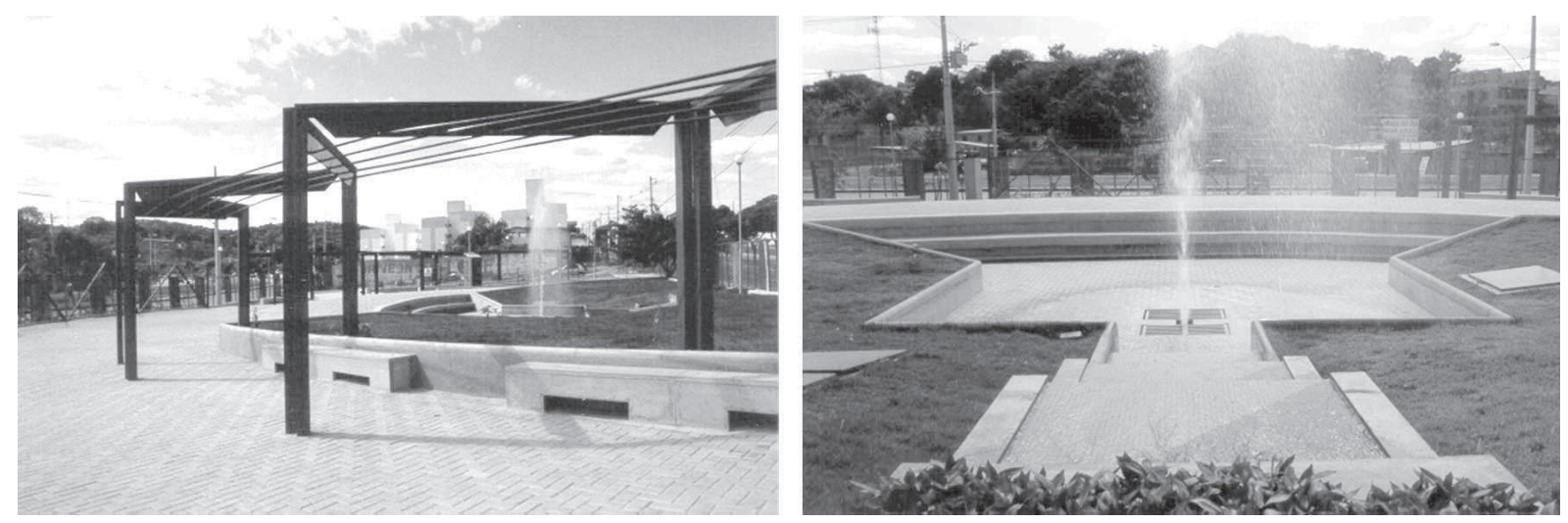

Figura 8: Paisagem criada Fonte: Acervo do autor
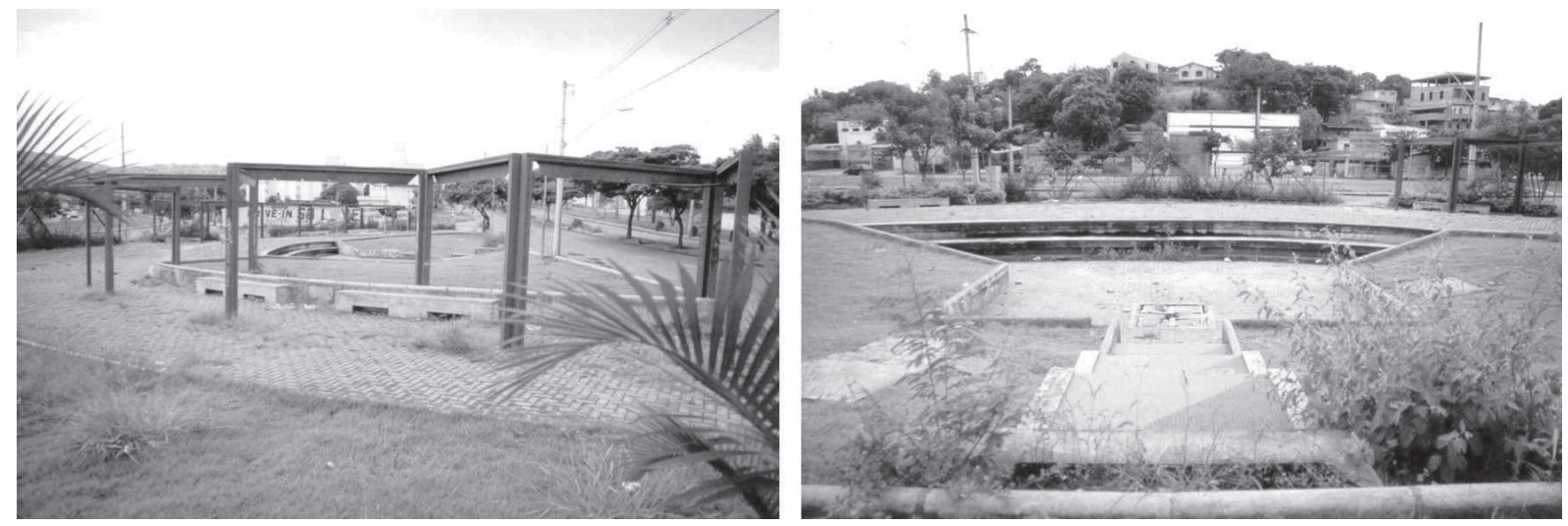

Figura 9: Paisagem reinventada Fonte: Acervo do autor

As praças possuem dois cenários marcantes e contrastantes: diurnos e noturnos. $\bigcirc$ uso público deve ocorrer em ambos já que esse é o objetivo da praça pública, ser usada por todos a qualquer hora. Dessa forma esses cenários devem ser estudados de forma que durante o dia os cenários, as cores, as formas e as texturas sejam atraentes ao uso público e não se percam no cenário noturno que deve ser tratado com recursos luminotécnicos adequados. Durante o dia, a praça e o entorno têm destaque. À noite ela marca sua presença no entorno.

A luz natural gera a cor, a volumetria e a silhueta das praças. Controla o brilho e estimula a vida na praça. A luz artificial permite o destaque noturno dos espaços e das paisagens, maximizando o uso público. Postes ornamentais, projetores e sinalizadores foram utilizados de forma a criar um cenário noturno com outras atividades e uma outra, praça.

A terra é o elemento suporte de todos os outros. É a partir dela que os demais elementos naturais e arquitetônicos são introduzidos. É o ponto de referência para o desenho das praças. Para o desenho interno da praça foram estabelecidos dois eixos de referência ortogonais como referencial geométrico e se amarra com as vias públicas. $O$ seu desenho é o resultado de malhas ortogonais a partir desses eixos sobrepostas ao relevo existente, objetivando a proporcionalidade e a harmonia de seu desenho interno e o externo.

projeto foi executado conforme procedimentos técnicos e aberto a fruição pública. As vias circundantes e os acessos de pedestres à praça não pode ser usada coletivamente porque não foi executado. Foi apropriada por apenas uma tribo e gradativamente foi sendo depredada e saqueada. A paisagem foi mais uma vez reinventada, de um espaço público se tornou privado, pois hoje a pérgula serve de moradia. 


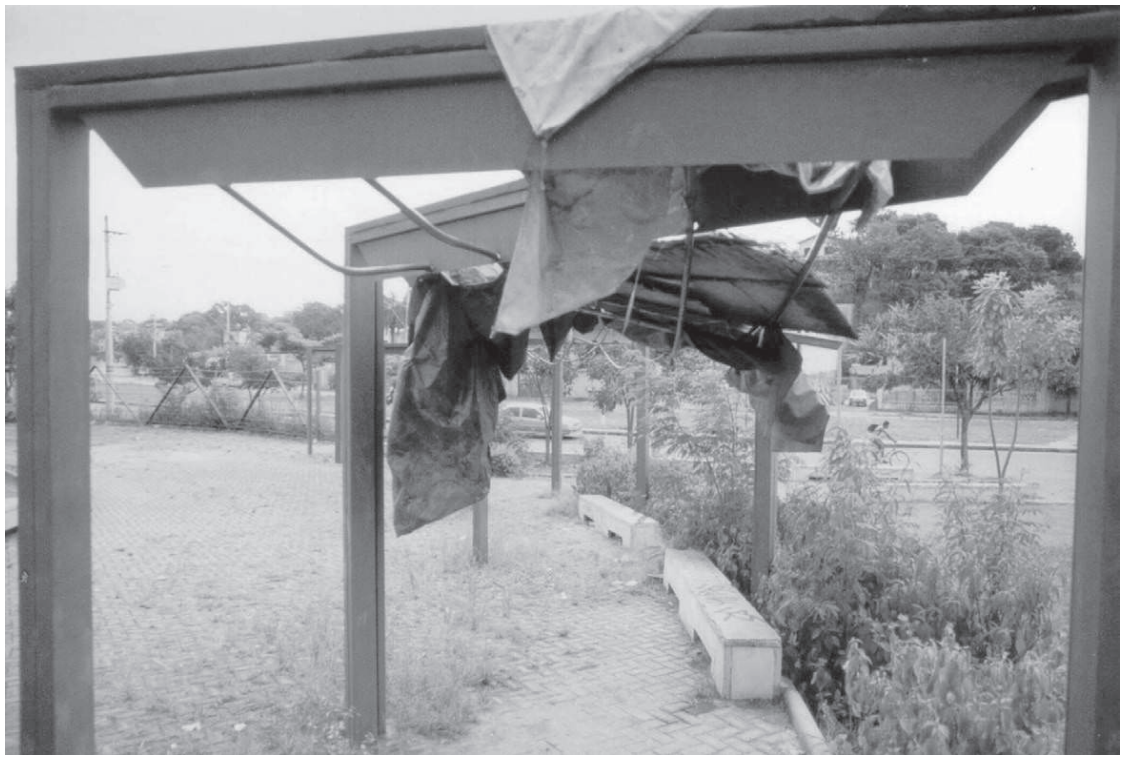

Figura 10: Moradia de um

sem teto

Fonte: Acervo do autor

Em 2006 foi solicitada, pelo Orçamento Participativo do Município, a duplicação da avenida Vilarinho. Uma das condicionantes como medida compensatória pelo impacto do empreendimento foi a implantação de uma praça para a região. Como conselheira do COMAM, sabedora da triste trajetória da praça João Alves, indiquei sua recuperação, já que a arquitetura paisagística é um instrumento que permite a preservação, recuperação, invenção e reinvenção de forma positiva da história da paisagem de cada lugar.

\section{5 - Conclusão}

As praças como espaços livres urbanos e públicos cumprem a função de "paradas", na circulação urbana. São os recantos que embelezam e maquilam a cidade e por onde a luz e o ar podem circular. Geralmente são cercados de edifícios (públicos ou privados) e algumas ruas que se interceptam nelas, ou nascem ou morrem nas praças. As praças são definidas pela forma da cidade, o seu tipo é definido pelo lugar onde se insere a acessibilidade, ambiência e expressão plástica e the conferem a personalidade e o valor urbano. Os elementos naturais e arquitetônicos harmonizados dão o valor estético, plástico e ornamental. A ambiência, os percursos, as atividades coletivas e o uso público refletem o seu valor sócio-cultural. É como o ambiente de "estar" da cidade, é a transferência da "casa" para a "cidade"; são também os ambientes de encontros, diversos e freqüentes espalhados em vários lugares da cidade. São recantos no dia-a-dia da rua e contam a história da cidade com marcos e símbolos refletindo épocas e estilos. A conduta, as normas e as posturas coletivas exigidas no convívio coletivo desses lugares constituem seu valor ético. A possibilidade da convivência entre a paisagem existente (ou original) com as paisagens reinventadas pela arquitetura paisagística são relevantes como valor ambiental.

Cada lugar gera um tipo de praça e cada praça pode gerar um novo lugar. A praça representa uma parte da cidade, uma parcela dos cidadãos. Várias praças representam a cidade e os cidadãos. Espero que a praça João Alves, dessa vez, consiga por meio da sua função pública desenvolver a urbanidade, a responsabilidade dos cidadãos, dos órgãos públicos com a cidade e suas paisagens. 


\section{Notas}

(1) "Paisagem não é a simples adição de elementos geográficos disparatados. É, em uma determinada porção do espaço, o resultado da combinação dinâmica, portanto instável, de elementos físicos, biológicos e antrópicos que, reagindo dialeticamente uns sobre os outros, fazem da paisagem um conjunto único e indissociável em perpétua evolução..." (BERTRAND, in TAUK, 1972)

(2) Praça (largo, platéia) é um lugar urbano projetado ou espontâneo, conforme a origem da cidade onde se localiza. Consiste em um espaço fechado pelas construções que geram sua ambientação e sua função pública. É um espaço livre por não haver nele edifícios, e é fechado pela ambiência da volumetria dos edifícios do entorno. A sua finalidade arquitetônica e ambiental é constituir um lugar atraente, social e saudável, contribuindo para a qualidade ambiental da cidade. Consiste em um espaço urbano cujo desenho externo é determinado pelo desenho da cidade, e seus limites físicos definem seu desenho interno. Configura-se e percebe-se o entorno envolvente e trabalha-se o espaço contido.

(3) Meio ambiente é tudo que rodeia o homem, quer como indivíduo, quer como grupo, tanto o natural como o construído, englobando o ecológico, o urbano, o rural, o social e mesmo o psicológico, de acordo com a definição da Unesco. É um sistema complexo e equilibrado, que engloba o sistema físico (ar/terra/luz/água), o sistema biológico (fauna, flora) e o sistema antrópico (social, cultural, político, econômico, estético e ético).

4) Espaços livres de uso público: são espaços de propriedade e de uso público, sem edificações ou com área edificada não-expressiva, onde existem elementos naturais - físicos e/ou biológicos - que justifiquem sua preservação, reabilitação ou transformação.

\section{Bibliografia}

CHOAY, Françoise. Urbanismo. São Paulo: Perspectiva, 1985.

COOPER MARCUS, Clare and Carolyn Francis. People places: Design guideness for urban open space. Califórnia: University of California Press, 1990.

FAVOLE, Paolo. La plaza en la arquitectura contemporánea. Barcelona: Gustavo Gilli, 1995.

HOLDEN, Robert. Diseño del espacio publico internacional. Barcelona: Gustavo Gilli, 1996.

LYNCH, Kevin. A imagem da cidade. Cambrige: Mass, 1960.

MACIEL, Marieta Cardoso. O projeto em arquitetura paisagística: Praças e parques públicos de Belo Horizonte. 1999. 200 p. Tese (Doutorado em Estruturas Ambientais Urbanas) - Faculdade de Arquitetura e Urbanismo da Universidade de São Paulo, São Paulo, 1999.

MACEDO, S. S.; ROBBA, F. Praças brasileiras. São Paulo: Edusp/Imprensa Oficial do Estado, 2002 (Coleção Quapá).

MINAS GERAIS. Programa metropolitano de parques urbanos. Belo Horizonte: Secretaria de Estado do Planejamento/ Belo Horizonte. Superintendência de Planejamento da Região Metropolitana de Belo Horizonte. 1975.

TAUK, Sâmia Maria. Análise ambiental: Uma visão multidisciplinar. São Paulo: Unesp, 1995.

WAGNer, A. M. et al. Praça João Alves. 2000. Trabalho (disciplina Paisagismo de Pós-graduação) - Escola de Arquitetura da UFMG, Belo Horizonte, 2000. 